\title{
Readers select a comprehension mode independent of pronoun: Evidence from fMRI during narrative comprehension
}

\author{
Franziska Hartung ${ }^{\mathrm{a}, \mathrm{b}, *}$, Peter Hagoort ${ }^{\mathrm{a}, \mathrm{b}}$, Roel M. Willems ${ }^{\mathrm{a}, \mathrm{b}, \mathrm{c}}$ \\ a Donders Institute for Brain, Cognition, and Behaviour, Radboud University, Nijmegen, The Netherlands \\ ${ }^{\mathrm{b}}$ Max Planck Institute for Psycholinguistics, Nijmegen, The Netherlands \\ ${ }^{\mathrm{c}}$ Centre for Language Studies, Faculty of Humanities, Radboud University, Nijmegen, The Netherlands
}

\section{A R T I C L E I N F O}

Article history:

Received 26 October 2016

Revised 16 March 2017

Accepted 25 March 2017

\section{Keywords:}

Narrative

fMRI

Perspective taking

Language

Comprehension

Simulation

Situation model

Personal pronouns

\begin{abstract}
A B S T R A C T
Perspective is a crucial feature for communicating about events. Yet it is unclear how linguistically encoded perspective relates to cognitive perspective taking. Here, we tested the effect of perspective taking with short literary stories. Participants listened to stories with 1st or 3rd person pronouns referring to the protagonist, while undergoing fMRI. When comparing action events with 1st and 3rd person pronouns, we found no evidence for a neural dissociation depending on the pronoun. A split sample approach based on the self-reported experience of perspective taking revealed 3 comprehension preferences. One group showed a strong 1 st person preference, another a strong 3rd person preference, while a third group engaged in 1st and 3rd person perspective taking simultaneously. Comparing brain activations of the groups revealed different neural networks. Our results suggest that comprehension is perspective dependent, but not on the perspective suggested by the text, but on the reader's (situational) preference.
\end{abstract}

(c) 2017 Elsevier Inc. All rights reserved.

\section{Introduction}

In most languages it is impossible to talk about an event without specifying the agent. Yet, we know relatively little about how the linguistically encoded agent relates to our cognitive representation of events. Some accounts argue that there are two systems underlying processing action language which might depend on perspective taking (Quandt \& Chatterjee, 2015). Experimental research has shown that the linguistic encoding of the agent of an event (e.g. with the use of personal pronouns referring to the agent) can have consequences for its cognitive representation. An action event is more likely to be represented from an observer's perspective when the agent of the action is referred to with a 3rd person pronoun (He is slicing the tomato) as compared to a potentially self-referential pronoun (you, I) (e.g., I am slicing the tomato). In contrast, self-referential pronouns can facilitate 1 st person perspective taking (Borghi, 2004; Brunyé, Ditman, Mahoney, Augustyn, \& Taylor, 2009; Brunyé, Ditman, Mahoney, \& Taylor,

\footnotetext{
* Corresponding author at: Center for Cognitive Neuroscience, Neurology Department, School of Medicine, University of Pennsylvania, Goddard Laboratory, Room 328, 3710 Hamilton Walk, Philadelphia, PA 19104, United States.

E-mail addresses: franziska.hartung@mpi.nl, fhartung@mail.med.upenn.edu (F. Hartung).
}

2011; Buccino et al., 2005; Ditman, Brunyé, Mahoney, \& Taylor, 2010; Sato \& Bergen, 2013; Tettamanti et al., 2005). Yet, simulating perspective does not seem to be necessary for comprehension (Brunyé, Ditman, Giles, Holmes, \& Taylor, 2016; Sato \& Bergen, 2013). In a recent study comparing pronoun-perspective interactions, Brunyé et al. (2016) showed that these effects are less robust for 1 st person pronouns and in narrative comprehension due to individual variation. Readers who self-report to be empathetic during reading are more likely to adopt a 1 st person perspective during reading of 1 st person narratives, whereas this was not the case for less empathetic readers. These individual differences seem to have a stronger effect for narratives than for individual sentences (Brunyé et al., 2016).

Personal pronouns are also considered important for narrative theory, because they are thought to influence how readers immerse into stories. Readers can get immersed in a story by either taking the role of an observer or by taking the viewpoint of one of the characters (Gerrig, 1999; Gerrig \& Jacovina, 2009; Oatley, 1999; Sanford \& Emmott, 2012). Being immersed in a story is linked to mental simulation (Jacobs, 2015; Zwaan, 2004) and defined as 'the state of feeling cognitively, emotionally, and imaginally immersed in a narrative world' (Gerrig, 1999; Green \& Brock, 2000; Green, Brock, \& Kaufman, 2004; Sestir \& Green, 2010). First person perspective narration is thought to invite a closer 
relationship between readers and characters (Stanzel, 1979) by making them share experiences and perceptions. It is therefore assumed that 1st person fiction feels more direct and immediate to the reader (Keen, 2007; see also Lodge, 2002). This means that in comparison with a 3rd person narration, 1 st person narration creates a stronger illusion of realism (Lodge, 2002; but see discussion in Keen, 2007) and promotes empathy and identification with fictional characters (Keen, 2007; see also Booth, 1983).

Using 1st or 3rd person pronouns referring to agents of actions also influence neural activation patterns. For instance, Рapeo, Corradi-dell'acqua, and Rumiati (2011) found that primary motor cortices are more strongly activated when reading action verbs in 1 st person as compared to 3rd person. In addition, Tomasino et al. (2007) found that sentences presented in 1st person relative to 3rd person, differentially activated areas in the posterior middle cingulate cortex (mPCC) and the left dorsal occipital cortex. There is further evidence for the tendency to adopt a 1 st person perspective when comprehending action verbs without context (Hauk, Johnsrude, \& Pulvermuller, 2004; Pulvermuller, 2005; Willems, Toni, Hagoort, \& Casasanto, 2010). There is also evidence for brain regions which are more involved in processing language in 3rd person. Papeo and Lingnau (2015) for instance showed that brain regions associated with the action observation network, like the posterior superior temporal gyrus (pSTS) and visual motion areas (MT), are more activated when an action verb is presented in 3rd person compared to 1st person, e.g. he grabs vs. I grab. This finding has been associated with the so called 3rd person bias effect in action observation, whereby activation levels within the action observation network are systematically higher when observing other agents performing an action as compared to perceiving movements or body parts from a 1st person perspective. This effect is taken as evidence for the higher salience of other agents and higher working memory demands based on the prediction of others' actions (Allison, Puce, \& McCarthy, 2000; see Peelen \& Downing, 2007 for an overview; Saxe, Jamal, \& Powell, 2006). If the 3rd person bias effect turns out to play a role in language comprehension as well, it might explain the finding that reading 3rd person stories is associated with increased arousal, as compared to 1st person stories (Hartung, Burke, Hagoort, \& Willems, 2016).

Differences in neural activation between the types of personal pronouns have been taken as evidence that the manner in which perspective is encoded linguistically affects whether an event is simulated in the 1 st or 3rd person perspective. Although perspective effects have been reported by multiple studies, there are several concerns. First, these effects might be a results of task and strategy rather than of stimulus properties (Gardner, Brazier, Edmonds, \& Gronholm, 2013; Tomasino \& Rumiati, 2013). In their comprehensive review on the role of motor representations in comprehension, Tomasino and Rumiati (2013) concluded that activations in primary motor areas during action verb comprehension are not a systematic effect of action language, but depend on task dependent strategies. Second, much of the research on perspective taking in language has focused on the comprehension of single words or sentences, when in fact perspective is especially crucial in regular communicative situations, where language comprehension depends on the context, such as in narratives or route descriptions. Third, there is little empirical work on perspective in literary reading (but see Hartung et al., 2016). With these limitations, it remains to be seen whether the effects of 1 st vs. 3rd personal pronouns are indeed guiding perspective taking systematically in more natural contexts.

\subsection{Aims of the present study}

To address the issues discussed above, the present study aimed to extend prior research on narrative perspective, as encoded by per- sonal pronouns, by investigating the neural correlates of simulating action events during narrative comprehension. In doing so we had 3 aims. First, we wanted to explore the relationship between text perspective and perspective taking in comprehension. Second, we wanted to test the influence of readers' preferences for perspective taking on comprehension and neural activations. Third, we wanted to determine whether there is evidence for a 3rd person bias effect for fiction comprehension, as indicated by stronger or broader activation of neural structures for 3rd person narratives, especially in the action observation network. Such an effect would be independent of whether perspective taking is based on text features or comprehension preference. In earlier work we proposed that narratives in the 3rd person perspective could induce a higher cognitive load compared to 1 st person perspective narratives (Hartung et al., 2016). We expected such an effect to be reflected in the form of increased activation levels in cortical areas associated with action observation, similar to the 3rd person bias effects in action perception (Peelen \& Downing, 2007).

In the present study, we tested the comprehension of stories in 1 st and 3rd person perspective, using 1 st or 3rd person pronouns that refer to the protagonist of the story in the agent's position. We refrained from including 2 nd person perspective because it is an uncommon form of narration which is typically limited to certain types of fiction only. This might lead to confounds regarding the comparability to 1 st and 3rd person narration and would affect the prior exposure participants have with this form of narration. Moreover, it has been shown that 2nd person pronouns tend to be interpreted in a generic meaning, particularly in descriptive language (de Hoop \& Tarenskeen. 2014).

We measured brain activity with functional MRI while participants listened to 2 literary stories, one from a 1st and the other from a 3rd person perspective. After each story, participants rated the story for appreciation and reading immersion. In order to dissociate strategy and pronoun effects (see discussion in Tomasino \& Rumiati, 2013), we also included a measure of subjective experience of mental imagery after each story, with two items directly addressing perspective taking. Here, participants indicated how much they experienced 1 st or 3rd person imagery during listening. We used a task in which participants listened to unintelligible speech as a baseline condition. We chose action events as a classical example of simulation to compare events with 1st and 3rd person pronouns because sufficient prior research was available to formulate clear hypotheses regarding brain areas associated with perspective.

\subsection{Hypotheses}

Based on the literature reviewed above we expected to find stronger activations for action events with 1st person pronouns compared to 3rd person pronouns in the sensorimotor cortices, as well as in the MPCC, the left dorsal occipital cortex and the dorsolateral prefrontal cortex (Saxe et al., 2006; Tomasino et al., 2007). For 3rd person pronouns compared to 1 st person pronouns we expected increased activation levels in the action observation network including right extrastriate body area (EBA) and left postcentral gyrus (Saxe et al., 2006), as well as pSTS and area MT, which both have previously been shown to be implicated in action language comprehension (Papeo \& Lingnau, 2015).

\section{Materials and methods}

\subsection{Participants}

Participants were 52 native speakers of Dutch (23 male, 29 female, mean age $=23.06$ years, s.d. $=3.40$, range $18-35$, 8 left 
handed) after exclusion of 8 participants (see Section 2.2) who listened to stories while undergoing MRI. The participants were naive to the purpose of the study, had no neurological or psychological problems, had normal or corrected-to-normal vision, and had no hearing difficulties. Written informed consent was obtained from each individual prior to the experiment, and ethical approval in line with the Declaration of Helsinki was obtained from the local ethics committee (CMO Committee on Research Involving Human Subjects, Arnhem-Nijmegen, Netherlands, protocol number 2001/095). Participants received monetary compensation at the end of the study.

\subsection{Data exclusions}

One participant aborted the experiment due to pain from wearing the headphones. Another participant was removed from the analysis because of falling asleep during a scan. Five more datasets were excluded from the analysis due to poor data quality because of artefacts from the scanner and/or excessive movement ( $>1$ voxel, $3.5 \mathrm{~mm}$ ). One additional dataset was removed due to scanner artefacts in the baseline condition. In total 8 datasets were removed from the analysis and all results reported are for $\mathrm{N}=52$ unless indicated otherwise.

The behavioral data of one task (appreciation rating, see below) from one participant could not be analyzed due to an error in the $\log$ file for one of the stories.

\subsection{Stimuli}

\subsubsection{Stories}

Two short stories from Dutch fiction, De Mexicaanse hond ('the Mexican dog') by Marga Minco (published 1990, 1236 words) and De muur ('the wall') by Peter Minten (published 2013, 1121 words) were used as stimuli for the experiment. Both were typical short stories describing a single incident in the respective protagonist's life. They had a limited number of characters, no introduction, and an open ending (see supplementary material S1 for translations of the stories). The stories were narrated with internal focalization, which means that the protagonist is always in focus, allowing readers to access the protagonists' mental states, and viewpoint which act as the source of construal for the events in the story reflecting her subjective perception.

In both original versions of the stories the protagonists are referred to with 1 st person pronouns (I, condition A). For the experiment a second version of each story was created by changing the personal pronouns that referred to the protagonist into their respective 3rd person forms (she, condition $\mathrm{B}$ ). Each participant was presented with both stories, one in condition $A$ and one in condition B, counterbalanced across subjects.

The stories were presented in an auditory manner. Stories were recorded at a regular speaking rate in a music recording studio by a native Dutch speaker. All versions of the stories were recorded in one shot and speech errors were corrected afterwards. The recordings were about $7 \mathrm{~min}$ long (De Mexicaanse hond: version $1=7 \mathrm{~min} 17 \mathrm{~s}$, version $2=7 \mathrm{~min} 23 \mathrm{~s}$; De muur: version $1=7 \mathrm{~min}$ $01 \mathrm{~s}$, version $2=7 \mathrm{~min} 04 \mathrm{~s}$ ). As a baseline condition we used the reversed audio signal of half of each story ( $7 \mathrm{~min} 25 \mathrm{~s}$; first half of De muur and second half of De Mexicaanse hond). For a volume test we used the first $56 \mathrm{~s}$ of another story (De invaller by Rene Appel, published 2003, excerpt $=157$ words).

\subsubsection{Appreciation rating}

Story appreciation was measured directly after listening. Participants were presented with 10 adjectives, which correspond to different dimensions of appreciation (translated into Dutch from Knoop, Wagner, Jacobsen, \& Menninghaus, 2016). The list consisted of the following items: interesting, well-written, of high literary quality, easy to understand, accessible, thrilling, beautiful, fascinating, emotional, and sad. Participants responded to the items on a 4point scale ranging from 'I totally disagree' (1) to 'I totally agree' (4) to how much the adjective describes the feelings evoked by the story.

\subsubsection{Emotional engagement with the protagonist and imagery}

A second questionnaire with 15 items tested (a) emotional engagement of participants with the protagonists ( 9 items), and (b) the experience of mental imagery during listening (6 items). The items were based on the emotional engagement and imagery scale of the story world absorption scale (SWAS, Kuijpers et al., 2014), with two additional items addressing perspective taking. The two additional items were 'At times, I had the feeling of seeing right through the eyes of the protagonist' (1st person perspective) and 'During reading, I saw the situations in my mind as if I was an eyewitness' (3rd person perspective). Participants responded to the items on a 4-point scale ranging from 'I totally disagree' (1) to 'I totally agree' (4).

\subsubsection{Individual differences}

We collected several measures for individual differences from each subject including the Vividness of Visual Imagery Questionnaire (VVIQ Marks, 1972/Marks, 1995) with some additional items, selfreported measures of reading preferences and behavior, the fantasy scale of the Interpersonal Reactivity Index (IRI, Davis, 1983), Need for Cognition (NCS, Cacioppo, Petty, Feinstein, \& Jarvis, 1996), Need for Affect (NAS, Maio \& Esses, 2001), Author Recognition Test (ART, Acheson, Wellu, \& MacDonald 2008; Koopman, 2015), and the Empathy Quotient (EQ, Baron-Cohen \& Wheelwright, 2004) questionnaire in this order (see below for details).

The reading habits and preferences consisted of 4 items. The first two items were 'How much attention do you pay to narrative and rhetoric style when reading a text or a book?', and 'Do you like reading fiction?'. Participants responded on a scale from 1 (not at all) to 7 (totally). An additional question asked 'How many novels did you read last year?'. This question was answered by a numerical estimate entered into an empty field by the participant. In the last item 'How often do you read fiction?' subjects chose between daily, more than twice per week, once per week, not regularly, and never.

In addition, we used the 6 items from the Fantasy scale of the IRI. IRI is a self-report measure of individual differences in empathy, consisting of 4 subscales. The Fantasy scale of the IRI tests individual readiness to get transported imaginatively into the feelings and actions of fictive characters in books, movies, and plays.

We used the NCS to measure motivation to solve complex tasks, and the NAS to assess motivation to approach or avoid emotions.

For an estimate of print exposure, we used a Dutch version of the ART. This standard measure contains 42 names, of which 30 are existent fiction authors and 12 made up names (see supplementary material S2). The score of each participant is computed by subtracting the sum of all incorrect answers from the sum of all correct answers. The total score can vary between -12 (only non-existent author names selected) to 30 (all correct names selected).

We also included the EQ questionnaire to measure individual differences in empathy, (standardized Dutch version http://www. autismresearchcentre.com/arc_tests).

\subsection{Procedure}

The experiment, including parts which are not relevant for the current report (see below), consisted of one session. After the participant was placed in the MRI scanner, the experiment began 
with a volume test, to adjust to subject-specific hearing levels. This involved listening to a fragment of a story that was not used in any other part of the experiment.

The first task consisted of listening to two recordings of the stories (one with 1 st and one with 3rd person pronouns). Participants listened to the two stories, separated by a brief pause. Each story lasted around $7 \mathrm{~min}$ (see above). The order of both story and pronoun condition were counterbalanced across participants. This means that $25 \%$ of participants listened to story A with 1 st person pronouns first (followed by story B in 3rd person), 25\% listened to story A with 3rd person pronouns first (followed by story B with 1st person pronouns), $25 \%$ listened to story B with 1st person pronouns first (followed by story A with 3rd person pronouns), and $25 \%$ listened to story B with 3rd person pronouns first (followed by story A with 1 st person pronouns).

Participants were instructed to listen to the materials carefully and attentively, and they were informed that this would be followed by questions on their appreciation of the story and narrative engagement. After each story, participants responded to the appreciation items, the emotional engagement, and mental imagery questions. This was followed by 3 more tasks which were presented in random order. One of the 3 tasks was a baseline condition in which participants listened to a reversed speech recording of the two story recordings. They were instructed to pay attention and listen carefully, even though comprehension was impossible. There was a break after each task and the participant decided when to continue. After the experiment, a ToM localizer task was conducted for reasons not reported here $(\sim 7 \mathrm{~min})$ followed by a high resolution anatomical scan $(\sim 5 \mathrm{~min})$. For all tasks in the scanner, participants gave responses with a 4-button response device with their right hand (index finger $=$ disagree $(1)$, little finger $=$ agree (4); numbers manually reversed for one participant who responded with the left hand due to hand injury).

After the scanning session, participants completed a post-scan test battery on paper ( $\sim 10 \mathrm{~min}$; see Section 2.3 .4 for details) including reading behavior and preferences, the Fantasy scale of the IRI (Davis, 1983), NCS (Cacioppo et al., 1996), NAS (Maio \& Esses, 2001), ART (Acheson et al., 2008; Koopman, 2015), and the EQ questionnaire (Baron-Cohen \& Wheelwright, 2004), in this order. In addition, all participants completed a modified online version of the VVIQ (Marks, 1972; Marks, 1995) as part of signing up for the experiment. The entire experiment took about $120 \mathrm{~min}$, including 70 min scanning time.

\subsection{Stimulus presentation}

Stimuli were presented with Presentation software (version 16.2, http://www.neurobs.com), and recordings were presented through MR-compatible earphones combined with hearing protection. All visual stimuli (questionnaires, instructions, etc.) were projected onto a screen using a projector outside the MR scanner room, which could be seen by participants through a mirror mounted over the head coil. Responses to the questionnaire items and the localizer task were recorded with a 4 button response device.

\subsection{FMRI data acquisition and pre-processing}

Images of blood-oxygen level dependent (BOLD) changes were acquired with a 3T Siemens Magnetom Trio scanner (Erlangen, Germany) with a 32-channel head coil. We used cushions and tape to minimize head movement. Functional images were acquired using a fast $\mathrm{T}^{*}$-weighted 3D EPI sequence (Poser, Koopmans, Witzel, Wald, \& Barth, 2010), with high temporal resolution (TR: $880 \mathrm{~ms}$, TE: $28 \mathrm{~ms}$, flip angle: 14 degrees, voxel size: $3.5 \times 3.5 \times 3.5 \mathrm{~mm}, 36$ slices $)$. High resolution $(1 \times 1 \times 1.25 \mathrm{~mm})$ structural (anatomical) images were acquired using an MP-RAGE T1 GRAPPA sequence. Data were pre-processed using the Matlab toolbox SPM8 (http://www.fil.ion.ucl.ac.uk/spm). After removing the first five volumes of each scanning block to control for T1 equilibration, images were motion corrected and registered to the first image of each scanning block. The mean of the motion-corrected images was co-registered with the individual participants' anatomical scan. The anatomical and functional scans were spatially normalized to the standard MNI template. Finally, all data were spatially smoothed using an isotropic $8 \mathrm{~mm}$ full width at half maximum (FWHM) Gaussian kernel.

\subsection{Data analysis}

\subsubsection{Behavioral}

Two-sided, paired $t$-tests were used to test for differences in behavioral responses to the questionnaires for personal pronouns (condition A vs. condition B). As a control analysis we additionally tested for between story differences (story A vs. story B). For a follow up analysis, the two perspective specific items from the imagery questionnaire were used to split the sample for perspective preference into 4 groups (see below).

\subsection{2. fMRI}

In order to create regressors for the analysis, the auditory recordings of the stories were scored for sequences containing action content in which the protagonist was the agent (see Kurby \& Zacks, 2013; Nijhof \& Willems, 2015 for a similar approach). We scored action verbs, implied actions (e.g. sound caused by action mentioned instead of the action itself), and sequences which express motion. In addition, the model also contained mentalizing events, which were used for a different analysis not reported here. Scoring was performed by three native speakers who were naive to the purpose of the study. In case of disagreement, a fourth native speaker was consulted.

De muur contained 46 action events, De Mexicaanse hond contained 26 action events. We controlled collinearity between regressors by calculating the Variance Inflation Factors (VIFs) for all regressors. VIFs were low $($ mean $=1.14$, median $=1.12$, range $=1.12-1.17$ ) and well below values considered critical for estimability of regressors (Kleinbaum, Kupper, Muller, \& Nizam, 1998; Mumford, Poline, \& Poldrack, 2015). At the single-subject level, statistical analysis was performed using a general linear model, in which beta weights for each regressor of interest are estimated for the time course of each voxel, using multiple regression analysis (Friston et al., 1995). Regressors were modelled as their true durations, and convolved with a canonical hemodynamic response function (Friston, Holmes, Poline, Price, \& Frith, 1996). A high pass filter of $128 \mathrm{~s}$ was added to the statistical model to remove very low frequency components of the signal. We assured that the spectral power of the regressors was at a higher frequency than the high-pass filter cut-off, in other words we assured that the regressors were not affected by the high-pass filter. The motion estimates of the motion correction algorithm were modelled as regressors of no interest to account for head motion. The same analysis was done on the data acquired while participants listened to the reversed speech fragments, for which the regressors are meaningless. This served as a baseline condition.

2.7.2.1. Whole brain analysis (WBA). We first performed a wholebrain group analysis in by contrasting the action regressor during story presentation between the two pronoun conditions (1st versus 3rd person pronouns). Results were corrected for multiple comparisons by combining a voxel-wise threshold of $p<0.005$ with a cluster extent threshold of 54 voxels for the first WBA and 68 voxels for the second WBA. These settings were obtained by 
performing a large number of randomizations (5.000) to assess which cluster extend level leads to control for false positives at a family-wise error rate of $5 \%$. The combinations of voxel level threshold with a cluster extend threshold is a good compromise between statistical sensitivity on the one hand and false positive error control on the other hand (Bennett, Wolford, \& Miller, 2009; Woo, Krishnan, \& Wager, 2014). The simulations took the amount of autocorrelation in the data into account, which leads to different thresholds for the two analyses (Bennett et al., 2009; Woo et al., 2014). The scripts used were taken from (https:// www2.bc.edu/ slotnics/scripts.htm).

To account for potential differences in strategies, independent of pronoun, a second WBA was performed in a split sample approach based on the behavioral responses to the two perspective-specific items in the imagery questionnaire. For both stories, individuals who scored greater than or equal to 3 (of 4 possible) for the 1st person item ('At times, I had the feeling of seeing right through the eyes of the protagonist') were grouped in the Enactor group $(\mathrm{N}=15)$. Individuals who scored greater than or equal to 2 on the 3rd person item ('While listening to the story, I saw the situations which were described in my head as if I was an uninvolved observer') were placed in the Observer group $(\mathrm{N}=14)$. The different threshold for these two items was because the medians for both items were different. Participants who scored above threshold for both items in both stories were labelled as Hypersimulators $(\mathrm{N}=12)$. The remaining participants $(\mathrm{N}=10)$ showed high variation without a consistent pattern and were excluded in the second analysis. In the WBA we compared Enactors and Observers directly with each other and Hypersimulators against the Enactor and Observer group. Independent sample $t$-tests were performed to compare whether Enactors and Observers differ on any of the individual differences variables tested in the post scan test battery.

For anatomical labelling we used the SPM Anatomy toolbox.

2.7.2.2. ROI analysis. We defined apriori ROIs based on previous fMRI studies (Papeo \& Lingnau, 2015; Saxe et al., 2006; Tomasino et al., 2007) and one TMS study (Papeo et al., 2011) in which an effect of perspective or pronoun was observed. The selected ROIs in which we expected increased activation for 1 st person action events were left and right primary motor areas (left MNI: -36 , $-19,48$; right 38, $-18,45$; Lacadie, Fulbright, Arora, Constable, \& Papademetris, 2008; pronoun effect reported by Papeo et al., 2011), medial posterior cingulate cortex $(-6,-54,2$; Tomasino et al., 2007), left calcarine gyrus $(-10,-76,16$; Tomasino et al., 2007), and right dorsolateral prefrontal cortex (51, 27, 27; Saxe et al., 2006). Increased activation for 3rd person during action events was expected in left posterior superior temporal sulcus (left pSTS; $-52,-50,5)$, left MT (-46, -61, 0; Papeo \& Lingnau, 2015), as well as right exastriate body area (EBA; $-6,-54,2)$ and left postcentral gyrus $(-12,-33,66$; Saxe et al., 2006). ROIs were spheres with an $8 \mathrm{~mm}$ radius and mean activations levels per regressor were extracted for each participant separately using the Marsbar toolbox (http://marsbar.sourceforge.net/) (Brett, Anton, Valabregue, \& Poline, 2002). The model was estimated for both event types (action and mentalizing), but we only report action events here. The analysis was done as paired sample ttests for each ROI comparing events with 1st and 3rd person pronouns.

\section{Results}

\subsection{Behavioral}

We observed a statistical trend for 1st person stories to be rated higher than 3rd person stories on easy to understand (appreciation questionnaire, mean difference $=0.33$, s.d. $=1.29, \mathrm{t}_{\mathrm{df}=50}=1.84$, $\mathrm{p}=0.07$ ) and more likely to evoke mental imagery of the situations narrated in the story (imagery questionnaire, mean difference $=0.26$, s.d. $=1.00, \mathrm{t}_{\mathrm{df}=50}=1.91, \mathrm{p}=0.06$ ). For all other items, we observed no significant differences between 1 st and 3rd person pronouns for either appreciation or the emotion or mental imagery items (all $|\mathrm{t}|<1.24, \mathrm{p}>0.21$ ). In contrast, for between story differences, we observed several statistically significant differences. Story B (De muur) was rated higher for appreciation by participants on the items well written (mean difference $=0.33$, s.d. $=1.07$, $\mathrm{t}_{\mathrm{df}=50}=2.22, \mathrm{p}<0.05$ ), easy to understand (mean difference $=0.45$, s.d. $=1.25, \mathrm{t}_{\mathrm{df}=50}=2.57, \mathrm{p}<0.01$ ), beautiful (mean difference $=0.41$, s.d. $=1.08, \mathrm{t}_{\mathrm{df}=50}=2.72, \mathrm{p}<0.01$ ), and emotional (mean difference $=0.45$, s.d. $=1.25, \mathrm{t}_{\mathrm{df}=50}=2.57, \mathrm{p}<0.01$ ) as compared to story A (De Mexicaanse hond). Moreover, story B was rated significantly higher on two items of the mental imagery questionnaire. Participants were more likely to report experiencing a mental image of the protagonist (mean difference $=0.48$, s.d. $=1.39, \mathrm{t}_{\mathrm{df}=50}=2.49$, $\mathrm{p}<0.05$ ) and the scenery in which the story took place (mean difference $=0.23$, s.d. $=0.73, \mathrm{t}_{\mathrm{df}=50}=2.28, \mathrm{p}<0.05$ ) for story B as compared to story A. In sum, for the behavioral measures we did not observe statistically significant differences for pronoun type, but we did observe statistically significant differences between stories, suggesting overall sufficient statistical sensitivity. For a complete overview over the behavioral results, see supplementary material (S3).

\subsection{FMRI}

Whole brain analysis: Null-effect of pronoun.

No contrast activations between 1st and 3rd person pronouns survived statistical thresholding. Below the corrected threshold, there were few activations and for completeness we report clusters with a minimum of 10 voxels. Two clusters showed higher activations for action events with 1st person pronouns as compared to 3rd person pronouns, in the left hippocampus $(k=49, x=-42$,

Table 1

Results of activations for 1 st and 3rd person pronouns in action events as compared to baseline.

\begin{tabular}{|c|c|c|c|c|c|c|}
\hline Contrast & Location & $\mathrm{x}$ & $\mathrm{y}$ & $\mathrm{z}$ & $\mathrm{T}$ max. & Nr. voxels \\
\hline \multirow[t]{7}{*}{ 1st person pronoun $>$ baseline } & \multirow[t]{3}{*}{ R precentral, postcentral gyrus } & 18 & -30 & 58 & 3.90 & \multirow[t]{3}{*}{439} \\
\hline & & 26 & -32 & 56 & 2.92 & \\
\hline & & 8 & -30 & 56 & 2.90 & \\
\hline & \multirow[t]{3}{*}{ L precentral, postcentral gyrus } & -20 & -28 & 54 & 3.61 & \multirow[t]{3}{*}{305} \\
\hline & & -22 & -26 & 62 & 3.47 & \\
\hline & & -18 & -36 & 54 & 2.99 & \\
\hline & L inferior occipital gyrus & -44 & -74 & -4 & 3.52 & 56 \\
\hline \multirow[t]{3}{*}{ 3rd person pronoun $>$ baseline } & $\mathrm{R}$ inferior occipital gyrus & 18 & -86 & -16 & 3.58 & 157 \\
\hline & \multirow[t]{2}{*}{ L middle temporal gyrus, hippocampus } & -40 & -6 & -22 & 3.53 & \multirow[t]{2}{*}{115} \\
\hline & & -34 & -12 & -22 & 2.81 & \\
\hline
\end{tabular}


Table 2

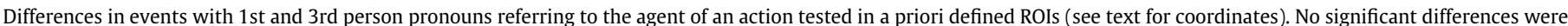
observed in any of the ROIs.

\begin{tabular}{|c|c|c|c|c|c|c|c|}
\hline ROI & Pronoun & Mean activation & s. d. & Mean diff. & s. d. & t-value $(\mathrm{df}=51)$ & p-value \\
\hline R M1 & $\begin{array}{l}\text { I } \\
\text { She }\end{array}$ & $\begin{array}{l}0.05 \\
-0.03\end{array}$ & $\begin{array}{l}0.40 \\
0.41\end{array}$ & 0.08 & 0.41 & 1.38 & 0.17 \\
\hline L M1 & $\begin{array}{l}\text { I } \\
\text { She }\end{array}$ & $\begin{array}{l}0.03 \\
-0.05\end{array}$ & $\begin{array}{l}0.35 \\
0.36\end{array}$ & 0.08 & 0.37 & 1.47 & 0.15 \\
\hline Right dorsolateral prefrontal cortex & $\begin{array}{l}\text { I } \\
\text { She }\end{array}$ & $\begin{array}{l}-0.10 \\
-0.08\end{array}$ & $\begin{array}{l}0.48 \\
0.42\end{array}$ & -0.02 & 0.47 & -0.35 & 0.73 \\
\hline Left dorsal occipital cortex & $\begin{array}{l}\text { I } \\
\text { She }\end{array}$ & $\begin{array}{l}-0.01 \\
-0.02\end{array}$ & $\begin{array}{l}0.54 \\
0.63\end{array}$ & 0.01 & 0.62 & 0.15 & 0.88 \\
\hline Medial posterior cingulate cortex & $\begin{array}{l}\text { I } \\
\text { She }\end{array}$ & $\begin{array}{l}0.13 \\
0.00\end{array}$ & $\begin{array}{l}0.80 \\
0.80\end{array}$ & 0.12 & 0.75 & 1.19 & 0.24 \\
\hline L posterior STS & $\begin{array}{l}\text { I } \\
\text { She }\end{array}$ & $\begin{array}{l}0.01 \\
0.04\end{array}$ & $\begin{array}{l}0.40 \\
0.37\end{array}$ & -0.03 & 0.41 & -0.44 & 0.66 \\
\hline L MT & $\begin{array}{l}\text { I } \\
\text { She }\end{array}$ & $\begin{array}{l}0.07 \\
0.03\end{array}$ & $\begin{array}{l}0.36 \\
0.35\end{array}$ & 0.04 & 0.34 & 0.90 & 0.37 \\
\hline R EBA & $\begin{array}{l}\text { I } \\
\text { She }\end{array}$ & $\begin{array}{l}0.13 \\
0.00\end{array}$ & $\begin{array}{l}0.80 \\
0.80\end{array}$ & 0.12 & 0.75 & 1.19 & 0.24 \\
\hline L postcentral gyrus & $\begin{array}{l}\text { I } \\
\text { She }\end{array}$ & $\begin{array}{l}0.07 \\
0.05\end{array}$ & $\begin{array}{l}0.26 \\
0.30\end{array}$ & 0.02 & 0.24 & 0.57 & 0.57 \\
\hline
\end{tabular}

Table 3

Resulting activation clusters of comparing action events in Enactors with the observer group and vice versa as well as shared activations between Enactors and Observers.

\begin{tabular}{|c|c|c|c|c|c|c|}
\hline Contrast & Location & $\mathrm{x}$ & $\mathrm{Y}$ & z & $\mathrm{T} \max$ & $\mathrm{Nr}$ voxels \\
\hline \multirow[t]{2}{*}{ Enactors $>$ Observers } & \multirow[t]{2}{*}{$\mathrm{R}$ frontolateral pole } & 16 & 60 & 10 & 4.49 & \multirow[t]{2}{*}{96} \\
\hline & & 18 & 58 & 2 & 3.36 & \\
\hline \multirow[t]{26}{*}{ Observers > Enactors } & \multirow[t]{3}{*}{ L middle and inferior occipital gyrus/lingual gyrus } & -10 & -96 & 0 & 4.95 & \multirow[t]{3}{*}{1576} \\
\hline & & -16 & -92 & 8 & 4.32 & \\
\hline & & -18 & -86 & -2 & 4.17 & \\
\hline & \multirow[t]{3}{*}{ R middle and inferior occipital gyrus, lingual gyrus, calcarine gyrus } & 26 & -86 & 8 & 4.52 & \multirow[t]{3}{*}{1127} \\
\hline & & 16 & -92 & -2 & 4.13 & \\
\hline & & 36 & -80 & -12 & 3.83 & \\
\hline & \multirow[t]{3}{*}{$\mathrm{R}$ inferior frontal gyrus } & 38 & 34 & 22 & 4.87 & \multirow[t]{3}{*}{503} \\
\hline & & 54 & 26 & 30 & 3.64 & \\
\hline & & 48 & 28 & 22 & 3.56 & \\
\hline & \multirow[t]{3}{*}{ L postcentral gyrus, supramarginal gyrus, posterior superior/middle temporal gyrus } & -54 & -18 & 48 & 4.46 & \multirow[t]{3}{*}{665} \\
\hline & & -58 & -36 & 16 & 4.03 & \\
\hline & & -56 & -24 & 20 & 3.92 & \\
\hline & L cerebellum & -34 & -60 & -50 & 4.29 & 91 \\
\hline & \multirow[t]{3}{*}{$\mathrm{R}$ posterior superior temporal gyrus } & 52 & -40 & 10 & 4.22 & \multirow[t]{3}{*}{324} \\
\hline & & 50 & -32 & 2 & 3.86 & \\
\hline & & 64 & -38 & 14 & 2.77 & \\
\hline & \multirow[t]{3}{*}{$\mathrm{R}$ middle temporal gyrus } & 44 & 2 & -26 & 4.15 & \multirow[t]{3}{*}{169} \\
\hline & & 56 & -6 & -22 & 4.12 & \\
\hline & & 62 & -14 & -18 & 2.87 & \\
\hline & \multirow[t]{3}{*}{$\mathrm{R}$ middle orbital gyrus } & 38 & 42 & -12 & 3.93 & \multirow[t]{3}{*}{109} \\
\hline & & 46 & 46 & -12 & 3.8 & \\
\hline & & 24 & 40 & -12 & 3.01 & \\
\hline & \multirow[t]{3}{*}{$\mathrm{R}$ caudate nucleus } & 20 & 2 & 22 & 3.47 & \multirow[t]{3}{*}{152} \\
\hline & & 22 & -8 & 22 & 3.43 & \\
\hline & & 28 & -12 & 32 & 3.07 & \\
\hline & $\mathrm{R}$ lingual gyrus & 16 & -72 & -12 & 3.21 & 71 \\
\hline \multirow[t]{14}{*}{ Enactors $\cap$ Observers } & \multirow{3}{*}{$\mathrm{L} / \mathrm{R}$ precentral sulcus, $\mathrm{L} / \mathrm{R}$ central sulcus } & 18 & -28 & 64 & 2.75 & \multirow[t]{3}{*}{1603} \\
\hline & & -4 & -26 & 70 & 2.63 & \\
\hline & & -24 & -20 & 64 & 2.56 & \\
\hline & \multirow[t]{2}{*}{ L/R cuneus } & 4 & -38 & 50 & 2.49 & 96 \\
\hline & & -6 & -32 & 48 & 1.65 & \\
\hline & $\mathrm{R}$ posterior insula & 44 & -6 & 6 & 2.46 & 138 \\
\hline & & 48 & 2 & 10 & 2.03 & \\
\hline & & 58 & 0 & 14 & 1.81 & \\
\hline & $\mathrm{R}$ thalamus & 18 & -40 & 6 & 2.44 & 347 \\
\hline & & 14 & -22 & 6 & 2.42 & \\
\hline & & 24 & -44 & 14 & 2.20 & \\
\hline & $\mathrm{R}$ posterior inferior temporal gyrus & 50 & -52 & -6 & 2.05 & 90 \\
\hline & & 54 & -58 & -12 & 1.92 & \\
\hline & & 52 & -42 & -8 & 1.75 & \\
\hline
\end{tabular}


$y=20, z=6, \operatorname{Tmax}=3.02, p<0.005$ uncor.) and in the right insula ( $\mathrm{k}=28, \mathrm{x}=42, \mathrm{y}=-14, \mathrm{z}=-8, \operatorname{Tmax}=2.90, \mathrm{p}<0.005$ uncor.), and 1 cluster showing higher activation for 3rd person as compared to 1 st person pronouns in the right middle and superior frontal gyrus ( $k=34, x=18, y=20, z=62, \operatorname{Tmax}=2.98, p<0.005$ uncor.).

For completeness, we report the results of the comparisons of the action regressors in 1 st and 3rd person pronoun conditions compared to the baseline. Events with 1 st person pronouns showed increased activations in the left and right precentral and postcentral gyri, as well as in left inferior occipital gyrus (see Table 1). Events with 3rd person pronouns on the other hand showed activations in right inferior occipital gyrus, and a region stretching from the left middle temporal gyrus (MTG) into the hippocampus (see Table 1 ).

\subsubsection{ROI analysis}

For the ROI analysis, a paired sample t-test (two-tailed) was conducted for each ROI, comparing the activations of events with 1 st or 3rd person pronouns. We observed no effect of pronoun in any of the ROIs (see Table 2).

\subsection{Split sample analysis}

To test if individual preferences in perspective taking can account for the absence of a pronoun effect on the group level, we used a split sample approach. Based on the behavioral responses to the two perspective items in the imagery questionnaire we identified 3 groups which showed a consistent pattern across both stories. Participants who scored high for 1st person perspective taking were grouped in the Enactor group $(\mathrm{N}=15)$, whereas those who scored high for 3rd person perspective taking were grouped in the Observer group $(\mathrm{N}=14$, see Section 2.7.2.1. for details). Participants who scored high for both items were put in a separate group labelled Hypersimulators $(\mathrm{N}=12)$.

During action events, Enactors compared to Observers showed higher activation in an area in the right frontolateral pole (area Fp1, see Bludau et al., 2014) (see Table 3 and Fig. 1). Observers compared to Enactors showed increased activations bilaterally in the occipital cortex and the lingual gyri. In addition, Observers as compared to Enactors showed activations in right inferior frontal gyrus, right posterior superior temporal gyrus and right middle temporal gyrus, right middle orbital gyrus, and right caudate nucleus, as well as left cerebellum and an area stretching from left postcentral gyrus to supramarginal gyrus and posterior superior and middle temporal gyri (see Table 3 and Fig. 1). A posthoc analysis of interaction between group and text perspective was conducted to see whether there is a within group effect for consistency of text perspective and perspective preference. Consistent with the results in the first analysis approach, there were no statistically significant activations associated with text perspective.

Shared activations of Enactors and Observers as indicated by a conjunction analysis (global) of both groups against baseline were found bilaterally in precentral and central sulci, cuneus, as well as right insula, right thalamus, and right posterior inferior temporal gyrus (see Table 3 and Fig. 1).

Participants who scored high for both 1 st and 3rd person perspective taking (Hypersimulators) showed activations (compared to reversed speech baseline) in a bilateral network with large overlaps with the networks of both the observer and the enactor group when comparing story comprehension with baseline (see Fig. 2 in purple, see supplementary material S4 for a table view of activations from Hypersimulators).

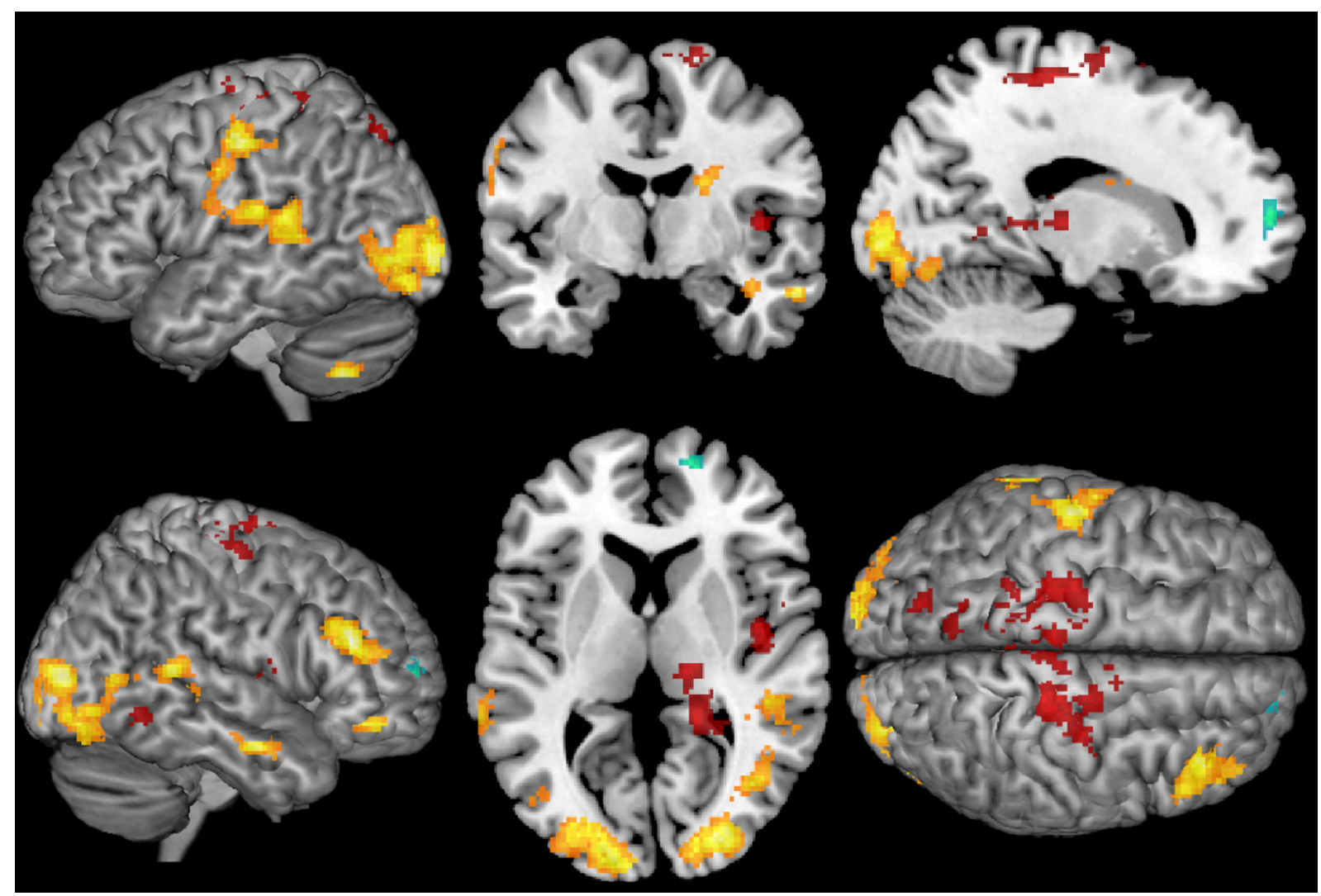

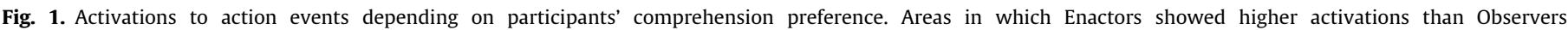

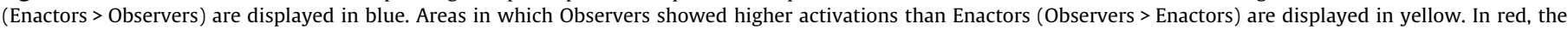
conjunction of both groups is plotted (Enactors $\cap$ Observers). All activations are significant at $\mathrm{p}<0.05$, corrected for multiple comparisons. 


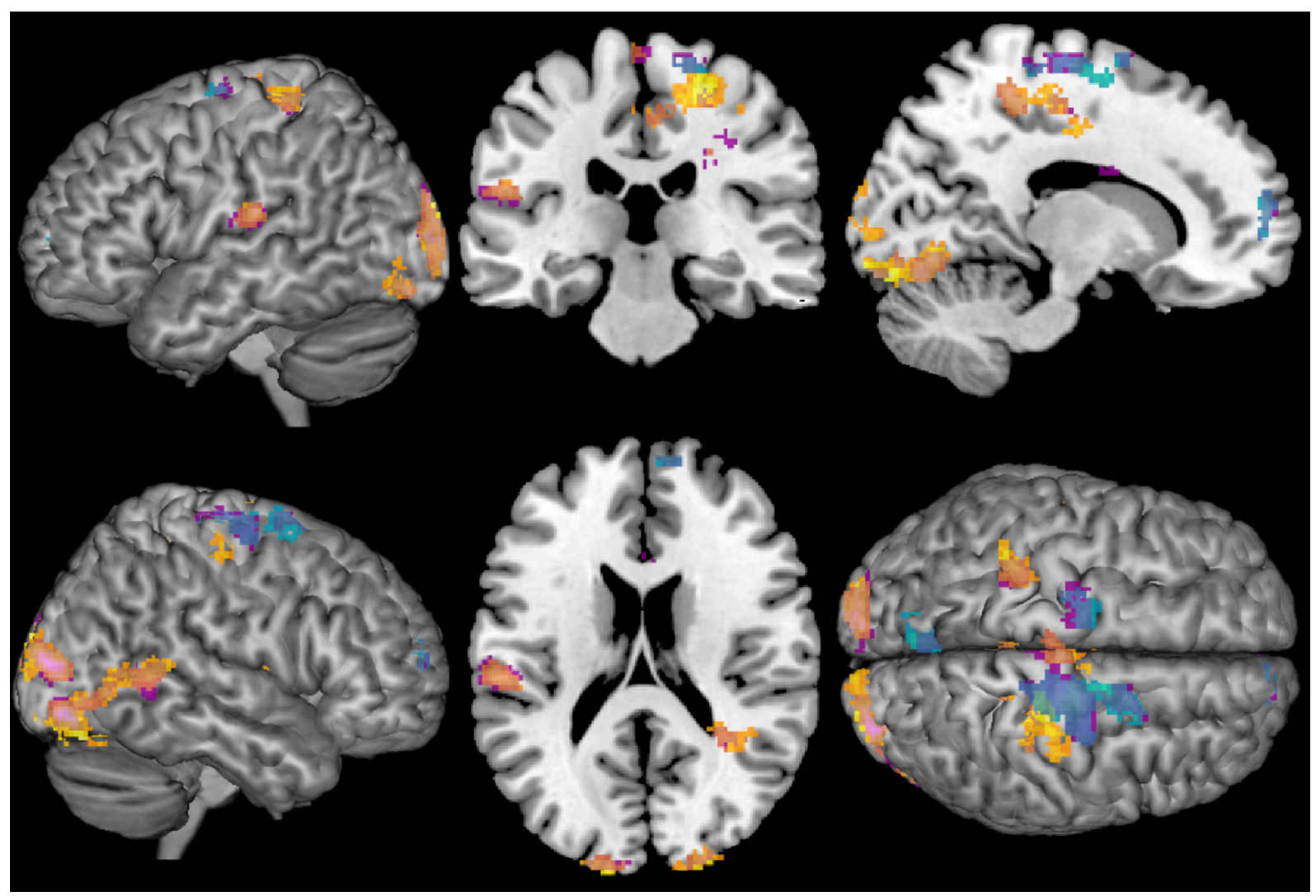

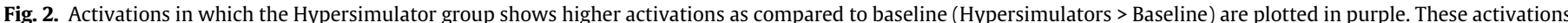

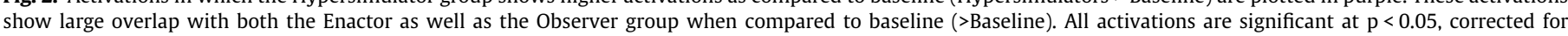
multiple comparisons.

\subsubsection{Individual differences}

There were no significant differences between Enactors and Observers for any of the individual differences measured in the post scan test battery (see supplementary material S5 Table 1). In the appreciation measure, the enactor group rated our two stories higher on the item well written (see supplementary material S5 Table 2 for details).

\section{Discussion}

In the present study, we tested the effect of perspective on neural activations during language comprehension. We manipulated perspective with 1 st or 3rd person pronouns that refer to the protagonist in literary narratives. Our results showed no evidence for an overall effect of perspective. Despite showing different focal areas of activation between the action regressors during listening and the low level baseline condition, no differences were found in the WBA when comparing events in 1st and 3rd person perspective directly with each other.

Given our relatively large sample size - compared to previous fMRI studies - and the combination of behavioral and neuroimaging methods, we were able to test whether individual differences accounted for the lack of difference between personal pronouns. We conducted a split sample analysis based on the behavioral responses to two items in which participants explicitly reported whether they took a 1 st or 3rd person perspective during comprehension. Indeed, readers seemed to employ different strategies in comprehension. We identified 3 modes in reading comprehension associated with perspective. However, these effects were not driven by narrative perspective, but rather by individual preferences in comprehension. Readers who scored high on the item, 'At times, I had the feeling of seeing right through the eyes of the protagonist' (Enactors) showed activations in a different network than readers who scored high on the question 'During reading, I saw the situations in my mind as if I was an eyewitness' (Observers). Another group seemed to simulate 1st and 3rd person perspective simultaneously (Hypersimulators), as evidenced by high scores on both behavioral items as well as large overlap in activated networks with both the enactor and the observer group.

Comparing brain activations of Enactors and Observers, we found significant differences between the two groups. When listening to action events, Enactors showed stronger activations in a region in the right frontolateral pole. In contrast, Observers showed stronger activations in visual areas bilaterally, which have been associated with motion processing (Braddick et al., 2001; Lui, Bourne, \& Rosa, 2007), and in the lingual gyri. Observers compared to Enactors additionally showed stronger activations in a network including the right inferior frontal gyrus, left postcentral gyrus, left supramarginal gyrus, and left and right posterior superior and middle temporal gyri. In addition, we found activations in right middle orbital gyrus, right caudate nucleus, and left cerebellum.

Shared activations between Enactors and Observers were found in (pre-) motor areas (bilaterally) and cuneus (also bilaterally) as well as in regions in the right insula, right thalamus, and right posterior inferior temporal gyrus. It is interesting that both Enactors and Observers, as well as Hypersimulators show activation in the same pre-motor and motor areas. It seems to be the case that these activations are independent of perspective. This can be taken as evidence that activation of motor cortices is important for understanding action semantics. However, involvement of motor cortices in language comprehension does not seem to reflect covert 
re-enactment as evidenced by the fact that the same regions of the cortex are also activated in readers who take a 3rd person perspective.

Our null-result for personal pronoun is at odds with some previous findings on pronouns being effective tools for guiding cognitive perspective. Even in the statistically more sensitive ROI analysis, where ROI choice was motivated by previous studies reporting pronoun effects, we did not find evidence for a pronoun-dependent modulation in neural activation. In fact, our findings provide evidence that comprehension is not affected by manipulating personal pronouns. A follow-up analysis for which we split the sample based on the individual preferences in perspective taking during comprehension however revealed relevant differences in neural networks associated with 1st or 3rd person simulating. What is striking when looking at the activations in Observers and Hypersimulators, as compared to Enactors, is the difference in the size of the neural networks being engaged during comprehension. Observers seem to recruit a much larger and wider network as compared to Enactors. This could be taken as evidence for increased saliency, working memory load, and processing difficulty similar to a 3rd person bias effect in action observation (Peelen \& Downing, 2007).

The suggestion that perspective effects in simulation are a matter of strategy more than experimental manipulation (the actual perspective in the text) has been raised before (see Tomasino \& Rumiati, 2013; see also Quandt \& Chatterjee, 2015) and is in line with other studies which report differences depending on what listeners pay attention to rather than stimulus properties (Cooper, Hasson, \& Small, 2011). In a very similar study, Brunyé et al. ( 2016) also found that readers differ in their individual predisposition for perspective taking during reading. Our study confirms this observation and adds direct experimental evidence that different reading styles are supported by different neural networks. Moreover, we showed that some readers simulate 1 st and 3rd person perspective simultaneously. This adds an alternative explanation to the absence of a perspective advantage in some readers. While the Brunye and colleagues conclude that this group does not simulate perspective at all during comprehension, these readers might in fact simulate both perspectives. It remains an interesting question for future research why individuals select a particular perspective over another to construct a mental model and how selection of this perspective relates to reading experience, and individual differences in spatial perspective taking abilities (Vukovic \& Williams, 2015).

The fact that both original stories were in 1st person perspective is a confound in our design which could have influenced our results. By having native speakers check the readability of the stories we tried to overcome this issue, but we cannot exclude the possibility that other features (beyond our pronoun manipulation) in the text could have influenced one pronoun condition more than the other. However, it is unlikely that modifications to one of the stories (from 1st to 3rd person) can account for the absence of an effect as we did not observe behavioral differences for the comparison between the two pronoun conditions (whereas we do find differences between stories). Another limitation of the study is that our interpretations are restricted to action events. For future research, we advocate the importance of accounting for different types of events and contexts.

Our results show that individuals can have different preferences for perspective taking when constructing situation models which affect the involvement of brain networks during comprehension. The insight that strategy or preference effects can overrule the effect of a well-established experimental manipulation is a valuable insight for future studies. This finding raises the question on how far experimental effects regarding linguistic perspective based on artificial stimuli can be generalized to more natural language.

\section{Declaration of interest}

Nothing to declare.

\section{Acknowledgements}

This project was funded by the Max Planck Society. We thank Jeffrey Martin and Paul Gaalman for help with the data acquisition. We also thank Sascha Jato, Yves Ardelt, and Anne Frericks for help with the recording the stimuli as well as Charlotte Poulisse and Gwilym Lockwood for helping with the translation of the stories into English.

\section{Appendix A. Supplementary material}

Supplementary data associated with this article can be found, in the online version, at http://dx.doi.org/10.1016/j.bandl.2017.03. 007.

\section{References}

Acheson, D. J., Wellu, J. B., \& MacDonald, M. C. (2008). New and updated tests of print exposure and reading abilities in college students. Behavior Research Methods, 40(1), 278-289.

Allison, T., Puce, A., \& McCarthy, G. (2000). Social perception from visual cues: Role of the STS region. Trends in Cognitive Sciences, 4(7), 267-278. http://dx.doi.org/ 10.1016/S1364-6613(00)01501-1.

Baron-Cohen, S., \& Wheelwright, S. (2004). The empathy quotient: An investigation of adults with asperger syndrome or high functioning autism, and normal sex differences. Journal of Autism and Developmental Disorders, 34(2), 163-175.

Bennett, C. M., Wolford, G. L., \& Miller, M. B. (2009). The principled control of false positives in neuroimaging. Social Cognitive and Affective Neuroscience, 4(4), 417-422. http://dx.doi.org/10.1093/scan/nsp053.

Bludau, S., Eickhoff, S. B., Mohlberg, H., Caspers, S., Laird, A. R., Fox, P. T., ... Amunts, K. (2014). Cytoarchitecture, probability maps and functions of the human frontal pole. NeuroImage, 93, 260-275. http://dx.doi.org/10.1016/j. neuroimage.2013.05.052.

Booth, W. C. (1983). The rhetoric of fiction. Chicago: University of Chicago Press.

Borghi, A. M. (2004). Putting words in perspective. Memory E Cognition, 32(6), $863-873$.

Braddick, O. J., O’Brien, J. M. D., Wattam-Bell, J., Atkinson, J., Hartley, T., \& Turner, R. (2001). Brain areas sensitive to coherent visual motion. Perception, 30(1), 61-72. http://dx.doi.org/10.1068/p3048.

Brett, M., Anton, J.-L., Valabregue, R., \& Poline, J.-B. (2002). Region of interest analysis using an SPM toolbox. Neurolmage, 16

Brunyé, T. T., Ditman, T., Mahoney, C. R., Augustyn, J. S., \& Taylor, H. a. (2009). When You and I share Perspectives: Pronouns modulate perspective taking during narrative comprehension. Psychological Science, 20(1), 27-32. http://dx.doi.org/ 10.1111/j.1467-9280.2008.02249.x.

Brunyé, T. T., Ditman, T., Mahoney, C. R., \& Taylor, H. A. (2011). Better you than I: Perspectives and emotion simulation during narrative comprehension. Journal of Cognitive Psychology, 23(5), 659-666. http://dx.doi.org/10.1080/ 20445911.2011.559160.

Brunyé, T. T., Ditman, T., Giles, G. E., Holmes, A., \& Taylor, H. A. (2016). Mentally Simulating Narrative Perspective Is Not Universal or Necessary for Language Comprehension. Journal of Experimental Psychology: LMC, 42(10), 1592-1605. http://dx.doi.org/10.1037/xlm0000250.

Buccino, G., Riggio, L., Melli, G., Binkofski, F., Gallese, V., \& Rizzolatti, G. (2005). Listening to action-related sentences modulates the activity of the motor system: A combined TMS and behavioral study. Cognitive Brain Research, 24(3), 355-363. http://dx.doi.org/10.1016/j.cogbrainres.2005.02.020.

Cacioppo, J. T., Petty, R. E., Feinstein, J. A., \& Jarvis, W. B. G. (1996). Dispositional differences in cognitive motivation: The life and times of individuals varying in need for cognition. Cognition, 119(2), 197-253.

Cooper, E. a., Hasson, U., \& Small, S. L. (2011). Interpretation-mediated changes in neural activity during language comprehension. Neurolmage, 55(3), 1314-1323. http://dx.doi.org/10.1016/j.neuroimage.2011.01.003.

Davis, M. H. (1983). Measuring individual differences in empathy: Evidence for a multidimensional approach. Journal of Personality and Social Psychology, 44(1), 113-126. http://dx.doi.org/10.1037//0022-3514.44.1.113.

de Hoop, H., \& Tarenskeen, S. (2014). It's all about you in Dutch. Journal of Pragmatics. http://dx.doi.org/10.1016/j.pragma.2014.07.001.

Ditman, T., Brunyé, T. T., Mahoney, C. R., \& Taylor, H. A. (2010). Simulating an enactment effect: Pronouns guide action simulation during narrative comprehension. Cognition, 115(1), 172-178. http://dx.doi.org/10.1016/j. cognition.2009.10.014.

Friston, K. J., Holmes, A., Poline, J. B., Price, C. J., \& Frith, C. D. (1996). Detecting activations in PET and fMRI: Levels of inference and power. NeuroImage, 4(3 Pt 1), 223-235. http://dx.doi.org/10.1006/nimg.1996.0074. 
Friston, K. J., Holmes, A. P., Worsley, K. J., Poline, J.-P., Frith, C. D., \& Frackowiak, R. S. J. (1995). Statistical parametric maps in functional imaging: A general linear approach. Human Brain Mapping, 2(4), 189-210. http://dx.doi.org/10.1002/ hbm.460020402.

Gardner, M. R., Brazier, M., Edmonds, C. J., \& Gronholm, P. C. (2013). Strategy modulates spatial perspective-taking: Evidence for dissociable disembodied and embodied routes. Frontiers in Human Neuroscience, 7(August), 457. http:// dx.doi.org/10.3389/fnhum.2013.00457.

Gerrig, R. J. (1999). Experiencing narrative worlds: On the psychological activities of reading. Westview Press.

Gerrig, R. J., \& Jacovina, M. E. (2009). Reader participation in the experience of narrative. The psychology of learning and motivation (1st ed., Vol. 51). Elsevier Inc.. http://dx.doi.org/10.1016/S0079-7421(09)51007-9.

Green, M. C., \& Brock, T. C. (2000). The role of transportation in the persuasiveness of public narratives. Journal of Personality and Social Psychology, 79(5), 701-721. http://dx.doi.org/10.1037//0022-3514.79.5.701.

Green, M. C., Brock, T. C., \& Kaufman, G. F. (2004). Understanding media enjoyment: The role of transportation into narrative worlds. Communication Theory, 14(4), 311-327. http://dx.doi.org/10.1093/ct/14.4.311.

Hartung, F., Burke, M., Hagoort, P., \& Willems, R. M. (2016). Taking perspective: Personal pronouns affect experiential aspects of literary reading. PLOS ONE, 11 (5), e0154732. http://dx.doi.org/10.1371/journal.pone.0154732.

Hauk, O., Johnsrude, I., \& Pulvermuller, F. (2004). Somatotopic representation of action words in human motor and premotor cortex. Cortex, 41, 301-307.

Jacobs, A. M. (2015). Neurocognitive poetics: Methods and models for investigating the neuronal and cognitive-affective bases of literature reception. Frontiers in Human Neuroscience, 9(April), 186. http://dx.doi.org/10.3389/ fnhum.2015.00186.

Keen, S. (2007). Empathy and the novel. Oxford University Press.

Kleinbaum, D. G., Kupper, L. L., Muller, K. E., \& Nizam, A. (1998). Applied regression analysis and other multivariable methods. Pacific Grove, CA: Brooks/Cole.

Knoop, C. A., Wagner, V., Jacobsen, T., \& Menninghaus, W. (2016). Mapping the aesthetic space of literature "from below". Poetics. http://dx.doi.org/10.1016/j. poetic.2016.02.001 (2015).

Koopman, E. M. (2015). Empathic reactions after reading: The role of genre, personal factors and affective responses. Poetics, 50, 62-79. http://dx.doi.org/ 10.1016/j.poetic.2015.02.008.

Kurby, C. A., \& Zacks, J. M. (2013). The activation of modality-specific representations during discourse processing. Brain and Language, 126(3), 338-349. http://dx.doi.org/10.1016/j.bandl.2013.07.003.

Lacadie, C., Fulbright, R., Arora, J., Constable, R., Papademetris, X., 2008. Brodmann Areas defined in MNI space using a new Tracing Tool in Biolmage Suite. Proceedings of the 14th Annual Meeting of the Organization for Human Brain Mapping; Melbourne, Australia. 2008. 771.

Lodge, D. (2002). Consciousness and the novel: Connected essays. Cambridge: Harvard University Press.

Lui, L. L., Bourne, J. A., \& Rosa, M. G. P. (2007). Spatial and temporal frequency selectivity of neurons in the middle temporal visual area of new world monkeys (Callithrix jacchus). European Journal of Neuroscience, 25(6), 1780-1792. http:// dx.doi.org/10.1111/j.1460-9568.2007.05453.x.

Maio, G. R., \& Esses, V. M. (2001). The need for affect: Individual differences in the motivation to approach or avoid emotions. Journal of Personality, 69(4).

Marks, D. F. (1995). New directions for mental imagery research. Journal of Mental Imagery, 19(3-4), 153-167.

Marks, D. F. (1972). Individual differences in the vividness of visual imagery and their effect on function. In P. W. Sheehan (Ed.), The function and nature of imagery, New York (pp. 83-108).

Mumford, J. A., Poline, J.-B., \& Poldrack, R. A. (2015). Orthogonalization of regressors in fMRI models. PLoS ONE, 10(4), e0126255. http://dx.doi.org/10.1371/journal. pone.0126255.
Nijhof, A. D., \& Willems, R. M. (2015). Simulating fiction: individual differences in literature comprehension revealed with FMRI. PloS One, 10(2), e0116492. http:// dx.doi.org/10.1371/journal.pone.0116492.

Oatley, K. (1999). Meeting of minds: Dialogue, sympathy, and identification in reading fiction. Poetics, 26, 439-454.

Papeo, L., Corradi-dell'acqua, C., \& Rumiati, R. I. (2011). "She" is not like "I": The tie between language and action is in our imagination. Journal of Cognitive Neuroscience, 23(12). http://dx.doi.org/10.1162/jocn.

Papeo, L., \& Lingnau, A. (2015). First-person and third-person verbs in visual motion-perception regions. Brain and Language, 141, 135-141. http://dx.doi.org/ 10.1016/j.bandl.2014.11.011.

Peelen, M. V., \& Downing, P. E. (2007). The neural basis of visual body perception Nature Reviews. Neuroscience, 8(8), 636-648. http://dx.doi.org/10.1038/ nrn2195.

Poser, B. A., Koopmans, P. J., Witzel, T., Wald, L. L., \& Barth, M. (2010). Three dimensional echo-planar imaging at 7 T. NeuroImage, 51(1), 261-266. http://dx doi.org/10.1016/j.neuroimage.2010.01.108.

Pulvermuller, F. (2005). Brain mechanisms linking language and action. Nature Reviews Neuroscience, 6(July), 576-582.

Quandt, L. C., \& Chatterjee, A. (2015). Rethinking actions: Implementation and association. Wiley Interdisciplinary Reviews: Cognitive Science, 6(6), 483-490. http://dx.doi.org/10.1002/wcs.1367.

Sanford, A. J., \& Emmott, C. (2012). Mind, brain, narrative. Cambridge: Cambridge University Press.

Sato, M., \& Bergen, B. K. (2013). The case of the missing pronouns: Does mentally simulated perspective play a functional role in the comprehension of person? Cognition, 127(3), 361-374. http://dx.doi.org/10.1016/j.cognition.2013.02.004.

Saxe, R., Jamal, N., \& Powell, L. (2006). My body or yours? The effect of visual perspective on cortical body representations. Cerebral Cortex, 16(2), 178-182. http://dx.doi.org/10.1093/cercor/bhi095.

Sestir, M., \& Green, M. C. (2010). You are who you watch: Identification and transportation effects on temporary self-concept. Social Influence, 5(4) 272-288. http://dx.doi.org/10.1080/15534510.2010.490672.

Stanzel, F. K. (1979). Theorie des Erzählens. Göttingen: Vandenhoeck \& Ruprecht.

Tettamanti, M., Buccino, G., Saccuman, M. C., Gallese, V., Danna, M., Scifo, P., ... Perani, D. (2005). Listening to action-related sentences activates fronto-parietal motor circuits. Journal of Cognitive Neuroscience, 17(2), 273-281. http://dx.doi. org/10.1162/0898929053124965.

Tomasino, B., \& Rumiati, R. I. (2013). At the mercy of strategies: The role of motor representations in language understanding. Frontiers in Psychology, 4(February), 27. http://dx.doi.org/10.3389/fpsyg.2013.00027.

Tomasino, B., Werner, C. J., Weiss, P. H., \& Fink, G. R. (2007). Stimulus properties matter more than perspective: An fMRI study of mental imagery and silent reading of action phrases. NeuroImage, 36(SUPPL. 2), T128-T141. http://dx.doi. org/10.1016/j.neuroimage.2007.03.035.

Vukovic, N., \& Williams, J. N. (2015). Individual differences in spatial cognition influence mental simulation of language. Cognition, 142, 110-122. http://dx.doi. org/10.1016/j.cognition.2015.05.017.

Willems, R. M., Toni, I., Hagoort, P., \& Casasanto, D. (2010). Neural dissociations between action verb understanding and motor imagery. Journal of Cognitive Neuroscience, 22(10), 2387-2400. http://dx.doi.org/10.1162/jocn.2009.21386.

Woo, C. W., Krishnan, A., \& Wager, T. D. (2014). Cluster-extent based thresholding in fMRI analyses: Pitfalls and recommendations. NeuroImage, 91, 412-419. http:// dx.doi.org/10.1016/j.neuroimage.2013.12.058.

Zwaan, R. A. (2004). The immersed experiencer: Toward an embodied theory of language comprehension. The Psychology of Learning and Motivation: Advances in Research and Theory, 44, 35-62. 